\title{
aCar - A Vehicle Concept for Sub-Saharan Africa
}

\author{
Martin Soltes ${ }^{1}$, Sascha Koberstaedt ${ }^{1}$, Simon Rauchbart ${ }^{2}$, Markus Lienkamp ${ }^{1}$, and Fritz \\ Frenkler $^{2}$ \\ \{soltes@ftm.mw.tum.de, koberstaedt@ftm.mw.tum.de, simon.rauchbart@tum.de\} \\ 1: Institute of Automotive Technology, Technical University of Munich, Germany \\ 2: Chair of Industrial Design, Technical University of Munich, Germany
}

\begin{abstract}
A team of researchers and students from Nigeria, Ghana and Germany has been working together since 2013 to design a new vehicle concept for Sub-Saharan Africa. This paper aims to analyze the mobility needs deriving from the vehicle concept fulfilling regional requirements at the very early stage of the aCar project. With Nigeria, Ghana and Kenya as a case study, the challenges have been shown to be the poor road conditions, road safety and the affordability of the vehicles. These countries showed the same picture of a huge mobility gap in rural areas, since a suitable vehicle that meets all requirements does not currently exist. The result of the research and design process is a vehicle concept that meets the needs of the people living in rural areas of Sub-Saharan Africa.
\end{abstract}

Keywords: Conceptual design, Design engineering, Participatory design, User centred design, Vehicle Concept

\section{Motivation}

This Word document can be used as a template for papers to be published in EAI Core Proceedings. Follow the text for further instructions on text formating, tables, figures, citations and references. Africa is an economically fast-growing continent. However, many people struggle to feed themselves due to structural problems and economic fluctuation. Especially in rural areas, there is no need for luxury, but a fundamental need for connection and mobility.

The goal of the research project "aCar mobility" is to generate a coherent vehicle concept that helps to reduce rural-urban migration and strengthen rural areas in a self-determined manner. A promising concept has to consider the specific market requirements and the resources available locally in order to address the heart of the problem as a "First Miles Vehicle".

The main focus, therefore, is demand-driven development of a multifunctional vehicle that primarily provides mobility for the individual and transport of people and goods as a possible commercial basis.

\subsection{Population}

Sub-Sahara Africa is the economic zone of all African countries south of the Saharan desert. In total, 46 countries belong to this region. With a population over 911 million, it is the 2nd most populated region in the world. One major problem for the infrastructure is the rapid growth of over $2.5 \%$ per year, accompanied by urbanization [1].

ACRID 2017, June 20-21, Victoria Falls, Zimbabwe

Copyright $(2017$

DOI 10.4108/eai.20-6-2017.2269976 


\subsection{Economy}

The economy of Sub-Sahara-Africa is on a very low level but in constant growth. The Gross Domestic Product (GDP) is an indicator of the economic health of a country as well as a gauge of standard of living [2]. The impact of the agricultural sector on GDP is especially high in the less developed countries high, as well as being the principal source of income. The number of people employed in agricultural businesses adds a comparatively low value to the GDP. The income of the people is adequately low.

Raising the productivity in the agricultural business increases welfare and the independence of rural communities. The current situation is that most African countries are not self-sufficient and rely on the import of basic foodstuffs. The reasons for this are according to Rakotoarisoa [3] low productivity, population growth and omissions in political and developmental aid. United Nations [4] postpones, that increasing economic growth and agricultural productivity is seen as the best and easiest way to fight poverty and hunger.

\subsection{Road Network}

The kind of roads and the density of the road network generates certain requirements for vehicles operating in Sub-Saharan Africa. Most roads are unpaved and the network does not cover the rural areas. Figure 1 depicts the total network of roads and its share of paved roads. Urbanization leads to traffic problems in the big cities and the number of vehicles is growing constantly.

Overall, the number of registered vehicles per thousand inhabitants is low and shows the economic potential in the region. Nigeria and Ghana, for instance, have a density of around 30 vehicles per 1,000 people whereas the number in Germany is 500 .

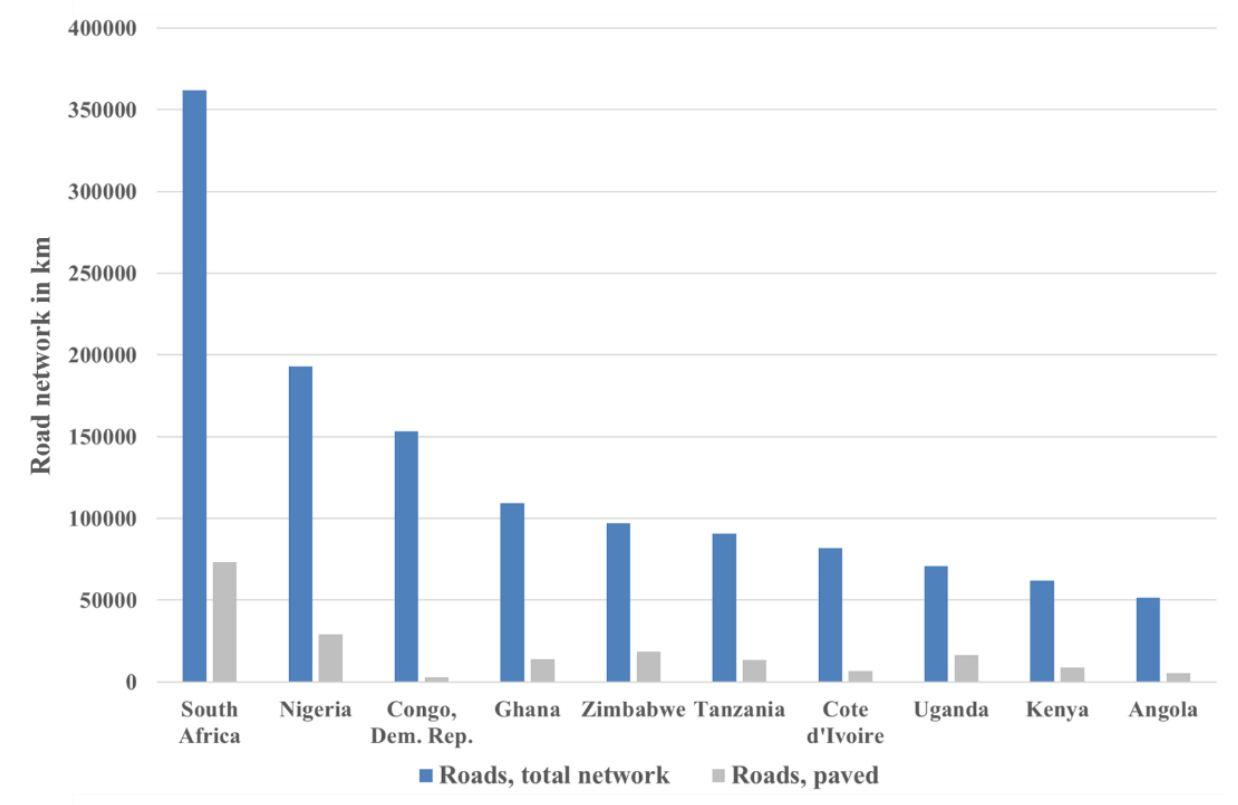

Fig. 1. The roads are mostly unpaved and the network is poor, data from World Bank [9]. 


\section{Approach in the Design Process}

Most of the data was acquired together with Kwame Nkrumah University of Science and Technology in Kumasi, Ghana, Federal University of Technology in Owerri, Nigeria and Dedan Kimathi University of Technology in Nyeri, Kenia. One source of information was excursions to car workshops, farms and food processing plants. In addition, expert interviews were held with taxi drivers, driving license authorities and experienced staff at the universities.

A survey was conducted in order to identify the demand, suggestions and the current situation concerning the mobility of potential customers. The results and experiences were discussed, presented and synthesized in workshops by research groups.

The Human Centred Design approach [5] was applied as part of a toolkit for finding new solutions in the developing world. The basis of this process builds the understanding of the user's world and its involvement in the product lifecycle. Requirements in terms of feasibility and viability are taken into account only once this step has been performed.

\subsection{Highest Demand in Rural Areas}

The imported vehicles are mainly developed with the focus on the American, European or Asian market. As long as infrastructure is sufficient, the car can be operated in Sub-Saharan Africa. Therefore, mobility of goods and people is already possible within cities and along built up roads.

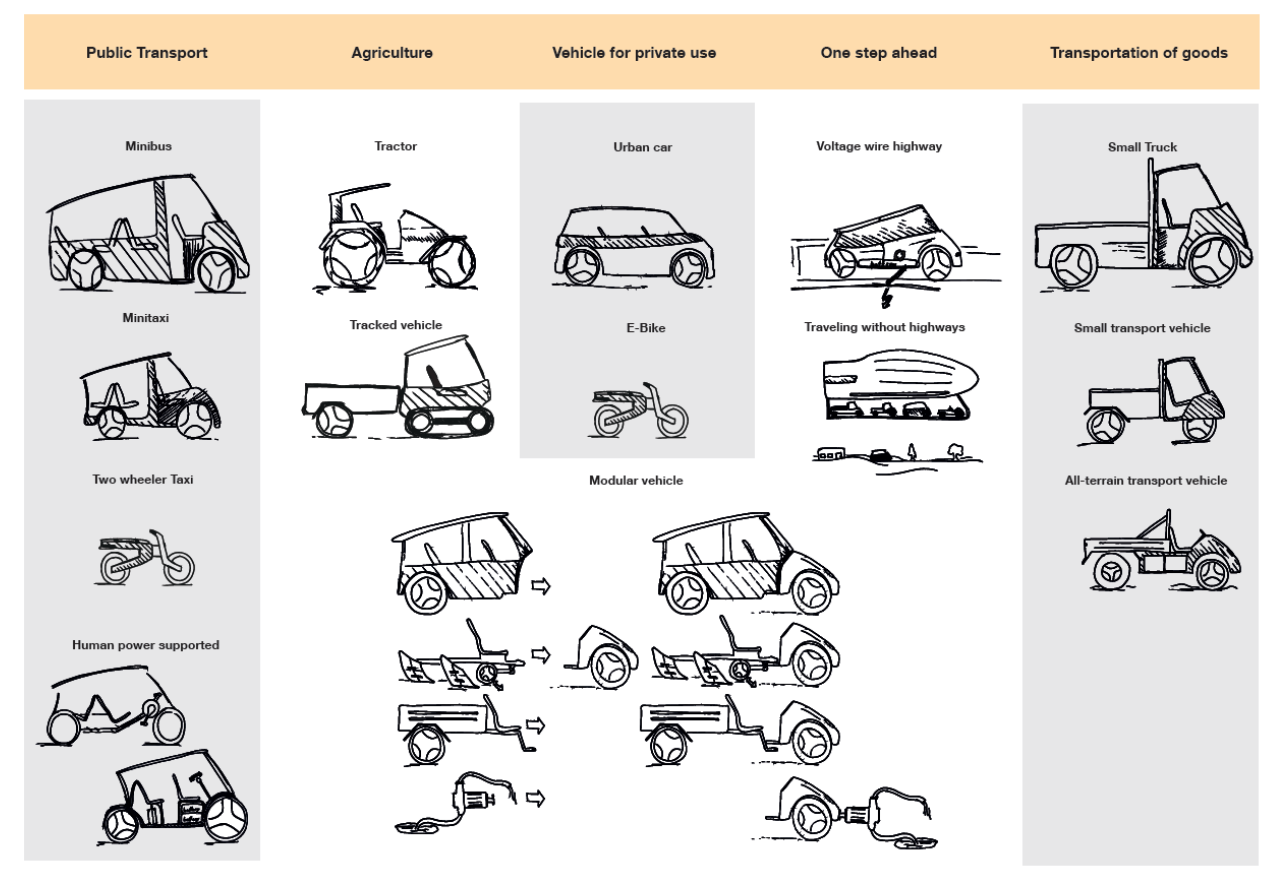

Fig.2. All vehicle categories considered for the aCar [6].

The situation in remote areas is different, as especially during rainy season, the roads present a challenge to those vehicles. Farmers are dependent on the transport of their products from the field to the market. If the supply chain is not guaranteed, the quality of the food is 
reduced, which leads to a reduction in the possible price that can be achieved at the market. There is definitely demand for a vehicle that ensures the transport of people and goods on rough roads, during all seasons.

The research indicates the biggest demand for a suitable vehicle concept in the rural areas in Sub-Saharan Africa. Due to the fragile supply chain and a very poor local public transport offerings, a gap in the vehicle market is created [7], which can be closed by the aCar vehicle. After deriving more than 20 concepts showed in Figure 2, the decision for a small multifunctional commercial vehicle was made. The aCar therefore represents a combination of a vehicle for agriculture and a minibus.

\subsection{Competitor Analysis}

The vehicles operating in Sub-Sahara Africa are mainly used cars, minibuses and trucks imported from Asia, Europe and the USA. The competitors for new vehicles are few. Klanner [7] showed, that of the new vehicle sales that do occur, most are Chinese motorbikes and three wheelers, as well as buses from India. European brands are not affordable for the majority of people. Used vehicles are sold at high prices and are often in poor condition.

\subsection{Vehicle Requirements}

With regard to the aim of the project, several boundary conditions need to be defined. The vehicle has to be produced and assembled in Africa. On the one hand, this avoids import restrictions, which leads to a lower price of the vehicle. On the other hand, this supports local business - an element that is emphasized further by the objective of using local materials were possible. During the development process, the climate conditions and environment have to be considered to reduce the emission impact. According to [8], the electronic architecture has to be robust in order to withstand these conditions and to guarantee easy repair and maintenance. The use of the vehicle has to be simple and intuitive. In the long run, production costs for the manufacturer and the total cost of ownership for the customer has to be comparable low in order to succeed in the target market. The main guideline for the design and development process is to keep the vehicle simple and smart.

\section{The Vehicle Concept}

The aCar is a versatile vehicle concept, developed and designed for the needs of rural regions in Sub-Saharan Africa.

There is a particular need for transportation of goods between the place of production of agricultural goods and the main road, accessible by major transport. In addition to this primary function, the vehicle can be transformed and used for public transport matters, carrying seven passengers plus one driver. 


\subsection{Concept Specifications}

The aCar concept vehicle provides specifications according to Table 1.:

Table 1. Basic specifications of the aCar.

All-wheel drive

Loading capacity of $800 \mathrm{~kg}$

Length $\mathrm{x}$ width $\mathrm{x}$ height $3.5 \mathrm{~m} \times 1.5 \mathrm{~m} \times 2.0 \mathrm{~m}$

$7+1$ passenger capacity

Electric range $80 \mathrm{~km}$

Top speed $60 \mathrm{~km} / \mathrm{h}$

Total cost of ownership < common tricycles on the market

The 4 wheel drive vehicle can carry cargo up to a total load of $800 \mathrm{~kg}$. For public transport purposes, the aCar is able to carry six persons on the cargo area and two persons in cab. The total range is about $80 \mathrm{~km}$, which covers the most of the acquired daily distances of future customers.

\subsection{Agricultural Area of Use}

One of the main characteristics of the vehicle is its off-road ability, realized with the allwheel drive and the high ground clearance of $40 \mathrm{~cm}$. As already mentioned, field work requires ground clearance and a compact vehicle layout. The width of the vehicle is only $1.5 \mathrm{~m}$ maximum and allows the vehicle to enter narrow spots between agricultural crops and other products [9]. An additional feature for transporting goods is the specially-designed loading area, illustrated by Figure 3.
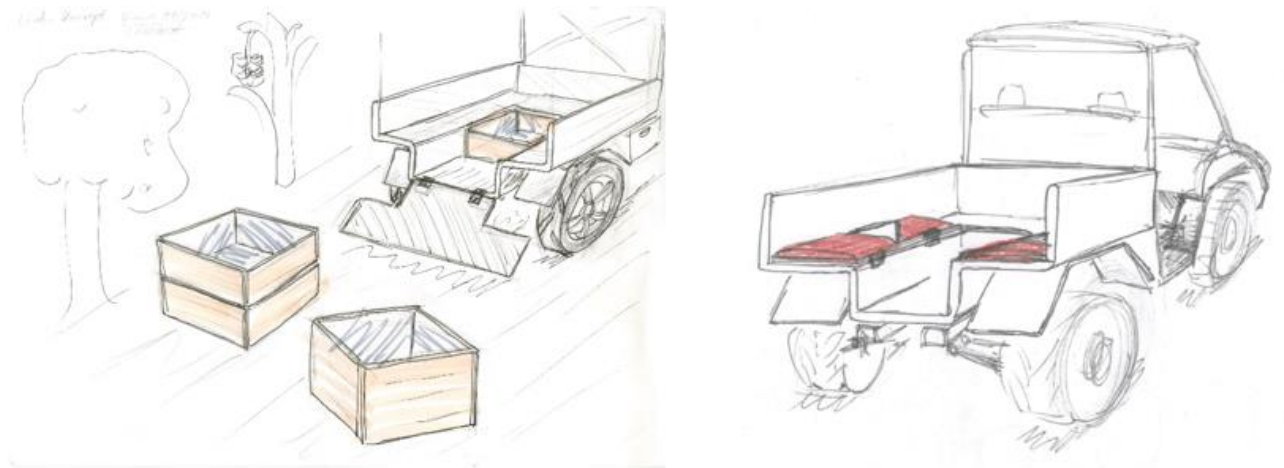

Fig. 3. The left draft shows a very efficient cargo concept with special-sized boxes, which fit exactly on the specially-designed load area of the aCar. (left) Flexible, foldable seat pads in the cargo area of the aCar for passenger transport (right) [6]

It is not only simple transport of goods that is important for farmers, but the processing of products directly on the field increases their productivity as well. The energy stored in the car battery can be used to run different appliances. This solution offers creative customers or suppliers the possibility of building simple appliances to process any agricultural goods. 
Some of the crops cultivated in the region are low in density and require a large platform for transportation. If the cargo area is full, the aCar also offers a tow hitch, which is compatible with a huge number of trailers on the market. As with the power take off, individuals have the option of designing and manufacturing their own devices for different special needs.

\subsection{Public Transport Area of Use}

The second use case of the versatile rural vehicle is public transport. The combination with the agricultural use case makes the aCar a promising concept for rural transport. Since most roads or paths are accessible only by high-tech off-road cars or, in most cases, bikes and animal-driven carts, the alternative aCar provides up to six seats on the specially-designed cargo area.

This aCar is different to the agricultural configuration in that it provides a special mechanism to flip foam seat pads onto each space in the passenger area within the cargo area. The illustration in Figure 3 on the right shows the mechanism described.

The lower part in the middle of the cargo area provides passenger comfort during travel. This gives the cargo area its function as a seat bench beside a cargo box system.

\section{The Vehicle}

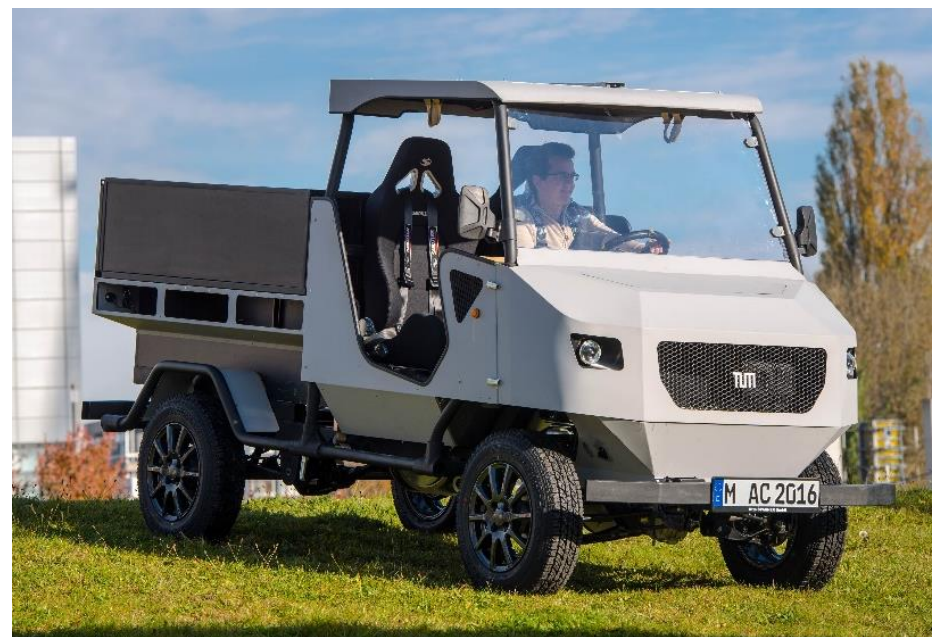

Fig. 4. The fully-functional prototype of the aCar, as presented to the public in May 2016

\subsection{Structure}

The basic structure shown in Figure 5 is provided by a ladder frame in combination with a revolutionary, ready-to-assemble frame, consisting of aluminum or steel tubes plugged and glued together via cast nodes. An industrial two-component adhesive is used for bonding, which, in addition to simple handling and low investment costs, also meets the strength requirements. In order to achieve the highest possible bending stiffness, the ladder frame is welded with cross braces. Using the welding process has the advantage that the assembly can 
be carried with even only a small degree of expertise and in a few production steps. The exterior parts consisting of 2D-metal sheets reinforced with wood panels are fixed to the frame through easy-to-install mounting clips. This innovative design allows even not-well-trained staff to build the whole car together in local garages.

The reasons for choosing materials and parts are simply the availability of these elements on the market, the cost effectiveness of those structures and the mechanical properties of the profiles.

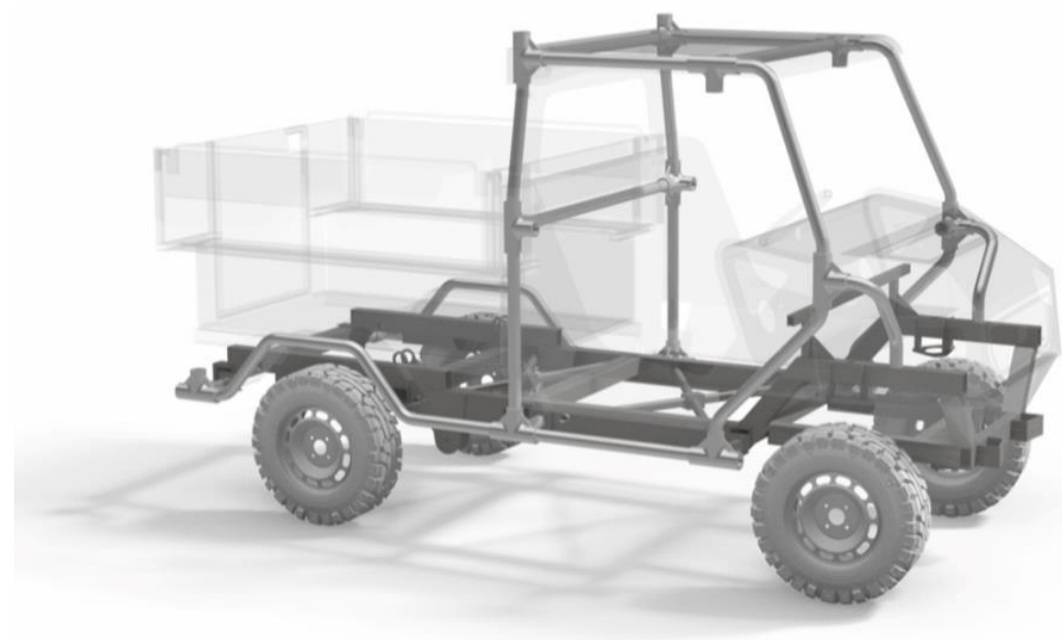

Fig. 5. This rendering shows the main structure of the aCar

\subsection{Drivetrain and Chassis}

Technical requirements are placed on the drive train in consideration of local conditions and the demand for good off-road suitability. Several primary drives were considered to be solvent-neutral and the technically optimum drive concept was chosen. The result of the consideration was that an electric drive is best suited to the concept, amongst others, because of the high torque profile at already low rotational speeds and the possibility of waiving a shiftable transmission and clutch due to a fixed transmission ratio.

The electric power train is developed regarding the vehicle requirements and the specification in Table 2. Due to simulations and competitor analysis, a total power of $16 \mathrm{~kW}$ and a battery capacity of $20 \mathrm{kWh}$ are sufficient. It is common for electric vehicles to use high voltage systems in order to reduce the current. High voltage requires special effort and knowledge to ensure the safety of the passengers during usage, service, repair and even emergency situations. This is not a practical solution for the target region, according to local research, due to the knowledge, tools and training available in common workshops. Therefore, the maximum voltage of the aCar is limited to $48 \mathrm{~V}$, which is within the range of the secure low voltage area below $60 \mathrm{~V}$.

The use of renewable energy resources such as solar, water, biogas or wind energy makes it possible to operate the vehicle with an environmentally-friendly footprint. Low-powered and dispersed power plants ensure the energy supply of remote areas. This allows communities to gain independence and keeps the net product local. The approach of using the vehicle batteries to stabilize the electric grid provides additional usage to the vehicle. 
Table 2. Specifications of the drivetrain.

Specification

Number of electrical motors

Type of drive

Machine type

Continuous power per machine

Voltage level drivetrain

Transmission ratio

\author{
Value \\ 2 \\ All-wheel drive \\ Claw pole \\ $8 \mathrm{~kW}$ \\ $48 \mathrm{~V}$ \\ Fixed
}

For the chassis, the goal is to implement a robust, simple and cost-effective system. The requirements set by the whole vehicle must be met by the target system. Influencing factors are the available space, spur widths and assumed load balances. An important criterion is that existing components can be accessed and independent development is not required.

According to studies, the conceptually-required properties can be best achieved by a McPherson wheel suspension on the front axle and a rigid axle on the rear axle. The front axle thus offers enough space to position all components in the front with respect to the package. The rear axle is designed with a rigid axle against overload and is state of the art for off-road vehicles.

\section{Economical Potential}

The aCar vehicle is designed for 2020. According to the World Economic Forum on Africa [10], the World Bank announced a past steady growth rate of $5 \%$ and the forecast reports the same for the coming years. Additionally, the number of middle-income families is growing. In 2014, UNICEF announced that Africa's population will double by 2050.

These facts are a very good starting position for this concept. Since the target group is focusing on the growing middle-income class, the future customer of the aCar will be able to afford it. Urbanization and food security are one of the major challenges facing the region and the entire world. The need for a vehicle like the aCar is constantly growing. The highest need for transportation both now and in the near future is in rural areas. Therefore, the versatile vehicle has a huge target group and economic potential. The population of the entire African continent is almost 1 billion people, with the 1 billion mark forecast to be passed by 2020 . Transport in urban areas is already facing critical capacity issues and realistic solutions are limited. The rural area and the semi-urban areas around urban centres have a huge potential to grow with the market demand.

\section{Discussion and Outlook}

An initial full functional prototype of the described vehicle concept already exists. Based on the requirements, the aCar provides mobility in rural areas for transporting goods and people. The decision to implement an electric powertrain is challenging for the target region. On the one hand, the concept provides a powertrain, which requires less maintenance and is easy to operate and repair. On the other hand, in combination with local power plants, it delivers independence from fossil fuel infrastructure. The vehicle concept offers a versatile 
use, whether for private, business or agricultural purposes. New business models are involved in selling, repairing and using the vehicle.

Based on the evaluation and results, further academic research has begun in order to derive a fully-functional vehicle for a serial production by 2020 .

\section{Acknowledgment}

This work was supported by the Bavarian Research Foundation with the project Rural Mobility in Developing Countries.

\section{References}

[1] World Bank (2014), World DataBank [online]. Available at: http://databank.worldbank.org/data/home.aspx (29.07.2014)

[2] Yamarone, R. (2012), "Gross Domestic Product", In; The Trader's Guide to Key Economic Indicators, Third Edition, John Wiley \& Sons, Inc., NJ, USA.

[3] Rakotoarisoa, M. (2011), "Why has Africa become a net food importer?", Food and agriculture organization of the United Nations, Rome.

[4] United Nations (2014), Poverty [online]. Available at:

http://www.un.org/Pubs/CyberSchoolBus/briefing/poverty/poverty.pdf (1.7.2014)

[5] IDEO (2011), "Human-Centered Design Toolkit: An Open-Source Toolkit to Inspire New Solutions in the Developing World", Authorhouse, 2nd edition.

[6] Maidt, M. (2014), "A Car - Vehicle concept for Sub-Sahara Africa", Unpublished design enterprise thesis, Technische Universität München.

[7] Klanner, M. (2014), "Beschreibung des für die Ableitung eines Fahrzeugkonzeptes für SubSahara Afrika zu durchlaufenden Prozesses", Unpublished semester thesis, Technische Universität München.

[8] Ott, M. (2014), " Entwurf und Implementierung des elektrischen Antriebsstranges eines Fahrzeugkonzeptes für Subsahara-Afrika", Unpublished master's thesis, Technische Universität München.

[9] Walcher, S. (2014), "Konstruktion und virtuelle Absicherung eines batterieelektrischen Fahrzeuges für den ländlichen Raum", Unpublished master's thesis, Technische Universität München. [10] World Economic Forum (2013), World Economic Forum on Africa [online]. Available at: https://www.weforum.org/events/world-economic-forum-on-africa-2013/ (13.12.2016) 